Christiane von Stutterheim*, Abbassia Bouhaous and Mary Carroll

\title{
From time to space: The impact of aspectual categories on the construal of motion events: The case of Tunisian Arabic and Modern Standard Arabic
}

DOI 10.1515/ling-2016-0038

Abstract: Motion events and their linguistic form have been studied extensively over the past decades from a typological as well as a psycholinguistic point of view. While many studies take Talmy's (1985. Lexicalization patterns: Semantic structure in lexical forms. In Timothy Shopen (ed.), Language typology and syntactic description: Grammatical categories and the lexicon, vol. 3, 57-149. Cambridge: Cambridge University Press, 2000. Toward a cognitive semantics. Cambridge: MIT Press) distinction as the starting point of their theoretical considerations, this twofold, lexicon-based typology has since been extended to capture the range of variation which languages display. Although the specifics of motion event conceptualization entail other factors in addition to space and lexical form, there are few studies on the implications of temporal categories. The aim of the present study is to document the role of aspectual categories in the construal of motion events, as observed in Tunisian Arabic (TA) and Modern Standard Arabic (MSA), two closely-related varieties with relevant contrasts in the types of verbal aspectual categories they encode. The analysis is based on descriptions of different types of motion events elicited on the basis of video clips. The findings reveal basic differences in the spatial and temporal categories selected for encoding-differences which are rooted in the respective linguistic systems: while TA, in contrast to MSA, has fewer forms to express directed motion via spatial concepts (path verbs, prepositions), its aspectual system is richer. The comparison indicates how the expression of directed motion in spatial terms in MSA is conveyed via temporal aspect (progression) in TA. In conclusion, the study outlines the case for the inclusion

\footnotetext{
*Corresponding author: Christiane von Stutterheim, Institute for German as a Foreign Language Philology, University of Heidelberg, Plöck 55, 69117 Heidelberg, Germany, E-mail: stutterheim@idf.uni-heidelberg.de

Abbassia Bouhaous: E-mail: bouhaous@idf.uni-heidelberg.de, Mary Carroll:

E-mail: carroll@idf.uni-heidelberg.de, Institute for German as a Foreign Language Philology, University of Heidelberg, Plöck 55, 69117 Heidelberg, Germany
} 
of temporal categories, in particular grammaticalized aspect, in approaches to the typology of motion events.

Keywords: spatial typology, motion events, Arabic varieties, verbal aspect, language production

\section{Introduction}

Motion events and their linguistic form have been studied extensively over the past decades from a typological as well as a psycholinguistic point of view, starting with the ground work on how language structures space (Miller and Johnson-Laird 1976; Talmy 1975, 1983; Herskovits 1986; Wunderlich and Herweg 1991; Klein 1991; Bloom et al. 1996). Talmy $(1975,1985,2000)$ was one of the first to focus on the area of motion events, developing the well-known typology of verb-framed and satellite-framed languages. In verb-framed languages information on the path of motion is encoded in the verb, often leaving manner of motion implicit, while satellite-framed languages encode manner of motion in the verb with information on the path in satellites. This typology has been elaborated further on the basis of a wide range of languages, including those which encode both path and manner in serial verb constructions (e. g., Chinese). While many studies take Talmy's distinction as the starting point of their theoretical considerations, an extensive range of cross-linguistic analyses has revealed a high degree of variation. Although the characteristics and implications of the verb- vs. satellite-framed type have been modified to varying degrees, questions concerning motion event typology and event conceptualization in this domain still focus on the concepts of manner and path and the consequences of the forms used to encode them cross-linguistically. The present study adds to this body of research by going beyond these two conceptual components to include the domain of temporality with regard to the role of grammaticalized aspect.

Languages differ in the formal means of expression in the domains of space and time, as reflected in the repertoire of manner verbs and the varying degrees of differentiation in the range of path verbs. Relevant conceptual categories also differ in the extent to which they are grammaticalized, as in the case of aspect, or case markers for the expression of spatial categories. The aim of the present study is to find out how differences of this kind affect the selection of conceptual categories in the expression of motion events. In addition to the role of lexical diversity in motion verbs and spatial prepositions, focus will be placed on the role of different systems of grammatical aspect in the construal of motion events. 
The approach taken is strictly empirical. We analyze how spatial and temporal concepts interact given the linguistic forms used in their expression. In the interpretation of the results, focus is placed on the following questions: in how far can the patterns of event construal be interpreted as arising from structural constraints in each language variety and to what extent can the findings be related on a typological level.

The study is innovative in that it investigates two languages that have not been studied and compared with regard to the expression of motion events. It is also the first cross-linguistic comparison of temporal concepts in these two languages which focuses the role of grammaticalized aspect in the construal of motion events, as evidenced on an empirical basis. ${ }^{1}$ In what follows, we will briefly sketch the central notions underlying the analyses. Since our primary interest concerns how speakers actually proceed when talking about motion events, the description of both linguistic systems is related to this aim.

\section{Basic concepts}

\subsection{Motion events and temporal concepts}

Motion events entail changes in location of an entity over time; therefore they are fundamentally anchored in the temporal domain. It is thus necessary to take into account the range of expressive devices used for anchoring an event in time, which may be grammaticalized as tense, while the devices for expressing the temporal relation between a viewing point, coupled with the inherent temporal contours of an event, are grammaticalized in many languages as viewpoint aspect and take very different forms (cf. Comrie 1976; Croft 2012). The latter category affects the event type by selecting different sub-phases of an event as reportable events, as the following examples illustrate:
(1) a. The man ran to his car
b. The man was running to his car

\footnotetext{
1 The interrelation between telicity (verbs denoting an end-state) and motion events was identified by Aske (1989) in determining use of the verb-framed pattern in Spanish. Bohnemeyer and Swift (2004) investigated both the role of verb meaning and grammaticalized aspect (viewpoint aspect) in Russian and Yukatek Maya where telic descriptions show an affinity for perfective viewpoints.
} 
In sentence (1a) the assertion includes the endpoint of the event, whereas in (1b) it remains open whether the endpoint is reached or not. Initial empirical analyses on the role of aspectual distinctions in structuring the path of motion investigated the effect of grammaticalized progressive/imperfective aspect (von Stutterheim and Nüse 2003; von Stutterheim et al. 2012). Speakers from two language groups (aspect and non-aspect) were asked to describe sets of motion events (a vehicle or person on its way from one place to another) and to tell what is happening. The question was as follows: would use of aspect lead speakers to focus on a specific phase of the event, or not, given the fact that aspectual distinctions (imperfective, progressive) lead to decomposition of the event into phases (this can be the inceptive, intermediate, or terminative phase). Significantly, the phase at which the moving entity actually reached the possible endpoint was not shown in the clips and had to be inferred. The phase selected for assertion in the present case, as observed for speakers of Modern Standard Arabic, Russian, English, Spanish (+ aspect) involved the intermediate phase, the phase between source and goal as focused in the clips. This was viewed as ongoing at the time of speech (a vehicle is driving along a road). In the languages without grammatical aspect (such as Dutch and German), by contrast, the perspective on the event also included mention of the endpoint. The perspective on the event is thus holistic (e. g., a vehicle drives along a road to a village). The findings correlated with speakers' direction of attention when traced via eye tracking: direction of attention to the endpoints of the events was in line with the temporal distinctions at issue and differed significantly for the two groups. Their role in directing attention is in evidence while observing the scene before speech onset. Based on these findings, the present study on motion events focuses on the role of spatial and temporal concepts in two language varieties which are closely related, but differ in the means available in the domains in question.

\subsection{Spatial concepts linked to entity in motion: the verb-framed pattern}

A motion event can be described by specifying the place at which the figure in motion, self-propelled or otherwise, starts to move (source), the place it is heading for (goal), and the path traced between the two. In the original typology developed by Talmy $(1975,1985)$, focus was placed on the type of information expressed in the verb, as opposed to a satellite. The point of departure in the analyses was thus linguistic form. Given the diversity as to what actually holds as a verb, or satellite, this basic categorisation has been repeatedly revised in 
order to cater for the range of cross-linguistic patterns observed (see Matsumoto and Slobin 2005). The basic question has been reformulated so as to focus on how the framing event, the path taken, is encoded, thus starting with the core event component path and not forms of expression. The motion event is treated as 'verb framed' when path is encoded in what is termed the verb root (a verb form that can occur on its own). Following Croft et al. (2010), any form that is not the verb root is analyzed as a satellite (see also Beavers et al. 2010; Bohnemeyer et al. 2007). Use of the term satellite varies in the literature, however, and as the forms in question in the present study are prepositions (cf. examples in Section 3.3.3 below) they will be referred to as such throughout.

From the point of view of event conceptualization, the category of path does not distinguish the types of concepts encoded in the verb root versus other forms: in the case of the verb the concepts typically relate to the figure in motion (e. g., orientation with respect to a destination as in to head for $x$, to approach $x$ ), which specify direction, while those encoded in forms such as prepositions are derived from contours of the ground (along, around, under). The consequences for event conceptualization were investigated in two empirical studies (Carroll et al. 2012; Flecken et al. 2015, which also included an eye tracking study). The framework of the study (video clips) is similar to von Stutterheim et al. (2012). The languages compared included two verb framed languages, French and Italian, as well as English and German, which are not. In French and Italian, spatial concepts in verbs relate to features associated with the figure in motion, as in se diriger vers 'to direct onself toward', avancer 'to advance', or s'approcher 'to approach'. Verbs can also include features of the ground such as traverser 'to cross' (relating to a place with two sides such as a road, square, playing field, see Talmy 1985). The relevance of the figure in motion in structuring the path is given with the core function of the verb in the verb-framed pattern.

However, constraints in describing the path of motion are observed when manner is encoded in the verb: if the verb is saturated with information on manner of motion in the verb-framed pattern, information on the path is unlikely to be encoded explicitly via forms which draw on contours of the ground (e. g., a bus is driving along a road) even though they are available in the language (as in French). Speakers focused on the figure in motion and specified its location only (e. g., une voiture roule sur la route, 'a car drives on the road'). Although French has forms which relate to the ground (e. g., prepositions such as le long de, 'along'), use was very low. A similar pattern focusing location was also observed for Italian.

In German and English, by contrast, which typically encode manner in the verb, speakers consistently expressed path via concepts relating to contours of the ground (prepositions such as around, along, over, under). The relevant 
constructions at form level include a component that refers to an object, the ground, and not the figure in motion. The documentation of the use of verbs is not new, but their implications at the level of the underlying concepts for the construal of motion events are relevant typologically.

The findings underline the extent to which path is prioritized in the verbframed pattern as encodable at the level of the verb root, which means that the underlying concepts are linked to the figure in motion. The core function of the figure in motion for event conceptualization in these languages was confirmed in a follow-up eye-tracking study with speakers of Italian and German using the same set of video clips. French speakers directed attention to the figure in motion to a significantly higher degree, in particular during event conceptualization before speech onset, in contrast to speakers of German, a language which is not verb-framed (Flecken et al. 2015). With a verb-framed pattern the information encoded in forms such as prepositions can be termed ground as location, but not ground as direction: the ground serves to locate the figure in motion but does not supply explicit information on contours of the path. This will also be investigated in the analyses of MSA and TA below.

The results illustrate how constraints at the level of linguistic form can be far reaching, given the types of spatial concepts they readily focus or not, and underline how event conceptualization differs for each pattern. As illustrated, the spatial concepts which verbs and prepositions encode differ fundamentally constructional constraints are core constraints.

\subsection{Terminology}

The languages under study, Tunisian and Modern Standard Arabic, are classified in the literature as verb-framed with information on the path of motion in the verb. In relation to the findings outlined above, MSA and TA will be analyzed with regard to the presence of the verb-framed pattern and the extent to which it holds in both languages. Path will be differentiated, where relevant, as path-figure where concepts relate exclusively to the figure in motion, as in head for $x$, approach $x$, or path-ground as in around $x$, up $x$. This contrasts with the term location, which does not relate to contours of the path (e. g., on the road). As mentioned above, spatial information of this kind is categorized as expressed in forms which correspond to the type "prepositional phrase". Goalrelated forms such as to, which require mention of the goal, are treated as directional terms. Terms of the type 'toward', which occur with path verbs in the present analysis, and also require mention of the goal, are described as designating a trajectory. 
As mentioned above, verbs can include both a figure and a ground component (to cross $x$, to ascend, to enter, to pass): with to cross the place in question is bounded at both sides, with to ascend there is a vertical orientation, while in the case of to enter the path leads across an outer boundary of a place from outside to inside, termed boundary crossing. Verbs that include a deictic component as in the case of to go and to come are viewed as encoding path in minimal terms. The verb go in the sense of go away, encodes motion away from a source. A deictic component may also be present in verbs such as to pass, as the point of reference, the entity passed by, can be a deictic point of observation. The verb can also relate to a feature of the ground.

\section{Tunisian Arabic (TA) and Modern Standard Arabic (MSA)}

The aim of the present study is to investigate the construal of motion events with regard to the role of aspectual categories on the basis of two language varieties, Tunisian Arabic (TA) and Modern Standard Arabic (MSA), which are closely related but differ in the types of verbal aspectual categories they encode. They both share many typological features but differ in the range of aspectual categories that are grammaticalized. This constellation allows the identification of the role of aspectual categories which is difficult to trace in languages that are less closely related. Given the complexity observed in the way relevant components interact, as outlined above, we assume that the investigation of varieties within one group of languages will assist in reducing this problem. In studies on the typology of motion events, MSA as well as oral Arabic varieties have received little attention as reflected in the extensive bibliography by Matsumoto and Slobin (2005) where there is no reference to Arabic. According to the criteria in Talmy (1985, 2000), MSA can be characterized as a verb-framed language, but in how far this applies for TA will be shown in the analyses below.

\subsection{The status of MSA}

The status of MSA is highly disputed in the field of research on Semitic languages. It is treated in many cases as an archaic artificial language (cf. Salameh 2010: 8) which should not be integrated into comparative studies. In other cases it is treated as "une langue vivante,... qui correspond à un besoin 
vital”' ['a language full of vitality... which corresponds to a vital need'] (Monteil 1960: 58). But what is the situation according to recent studies on Arabic diglossia (cf. Ryding 2011, 2005; Rouchdy 2002)? MSA is viewed as a standard language, shared by educated speakers across all Arabic countries in the role of a lingua franca. "MSA is now the written norm for all Arab countries as well as the major medium of communication for public speaking and broadcasting.... (It serves) as a resource language for communication between literate Arabs from geographically distant parts of the Arab speaking world." (Ryding 2011: 845)

MSA is the language of religion, literature, the official media, films, games. In the present context it is important to note that it is not only a written language, comparable to the role of Latin in the history of European countries (cf. Salameh 2010, who draws this comparison). Furthermore, MSA is used orally in formal speech, public lectures and debates, news broadcasts, and where educated speakers of different dialectal backgrounds communicate (cf. Ryding 2011: 846). While the written form of MSA conforms to uniform standards, the oral form exhibits a spectrum between a full form with all inflectional markers and a more colloquial form where inflectional markers are reduced. The formal difference between the written and the oral form of MSA is of little relevance, however, for the questions addressed in the present study, as the aspectual system in its categorical oppositions is not subject to morpho-phonological reduction.

Regarding MSA, the linguistic situation in Tunisia is characterized by diglossia as in all other Arabic countries. MSA is not acquired as a mother tongue which means that the onset of acquisition cannot be identified on a consistent basis across speakers. Children come into contact with MSA from an early age, but productive use of the language starts at school age. MSA is also the language in higher education in both formal and educational contexts, written as well as spoken. Educated speakers are thus bilingual with MSA as the official language in all formal contexts. ${ }^{2}$ Tunisian Arabic is acquired as a first language but does not have a written code. ${ }^{3}$

2 Most North African countries show a specific situation of diglossia in that French is still important academically in higher education and many in these countries are trilingual. However, influence from French can be neglected in the following since speakers of both groups MSA and TA had the same knowledge of French. So interference from French cannot account for the differences observed between the two groups of Arabic speakers.

3 There is a written version of TA which is used in electronic social media and informal contexts only. 


\subsection{The verb in Arabic}

The verb is formed by radicals, typically three, but there can be two or four. ${ }^{4}$ Full lexical status is attained when vowels are inserted between the radicals which are marked with respect to categorical, lexical, and grammatical meaning via vocalization and affixation of prefixes and suffixes: see for example, $\mathrm{d} \mathrm{x} \mathrm{l}^{5}$ 'being-inside': daxala (MSA): PF.3SGM' ; yadxulu (MSA): IPF.3SGM; dāxel (TA): AP.3SGM; duxūl (MSA): verbal noun. Arabic has no infinitive form (in terms of Latin grammar). The form in citations is the 3rd person masculine singular perfective, e. g., daxala. Verb forms from the transcribed data are quoted in the original form, as noted in the transcripts.

\subsection{Aspectual categories}

\subsubsection{Basic categories}

Aspect is a notoriously difficult category in semantic analysis. Core features have been disputed in countless studies, under different theoretical approaches. Instead of attempting to present some form of overview, we will introduce the framework and aspectual categories used in describing the two Arabic varieties in the present empirical study, starting with the basic distinction that has to be made between lexical or inherent semantic aspect and grammatical aspect (cf. Dahl 1985; Sasse 2002; Klein 1994; Croft 2012). Following Klein (1994), the analysis is based on the notion of situation types in relation to lexical aspect. Klein distinguishes three basic types which are characterized by the relation between qualitative and temporal properties of a situation: zero-state situations without any possible qualitative change (helium is a gas), one-state situations for which there are pre-states and post-states in which the situation does not hold (the child is running in the garden) and two-state situations which imply a change of state (The child left the house). In order to understand the interaction between lexical aspect and grammatical aspect, the different types of situations have to be classified according to the nature of the qualitative properties of the

4 The term Arabic is used to refer to all forms of Arabic in the present study. The term MSA is used to refer to the standard language, used as lingua franca across all Arabic countries, the term Arabic varieties (traditionally called dialects) is used for Arabic mother languages such as Tunisian, Moroccan, and Syrian Arabic.

5 For Arabic words we use the transliteration system of the Morgenländische Gesellschaft.

6 Abbreviations used in the following: PF (perfective), IPF (imperfective), AP (active participle), Vasp (aspectual co-verb $q \bar{a}$ ‘id (AP) 'sit', SG (singular), M (masculine), F (feminine). 
respective sub-states (cf. the discussion in Croft 2012: 2.4). Klein analyses these more fine-grained relations between temporal and qualitative properties of the sub-phases of events as time-argument structures (Klein 2010). We will focus in the following on the situation type targeted in the present study: motion events, in which one entity - the subject of the corresponding clause - changes its position. The verbal lexicon expressing such motion events can consist of both one-state and two-state situation types. One-state situations can be either directed i. e., with incremental (cf. Croft 2012: 62) changes towards a goal (the child walked towards the house) or they can be undirected (the child walked around). Two-state situations can differ with respect to the duration of the two states: in the child entered the room the verb describes only the transition between the two states (source state, target state); in the woman ran into the station, the change is preceded by an initial state (source state) ${ }^{7}$ which has duration.

Grammatical aspect operates on situations as expressed at the lexical level. It selects a specific subphase or subphases of a situation, as asserted by the respective sentence. Klein introduces the notion of topic time TT, the time interval for which the assertion is made. Grammatical aspect determines the relation between the time interval for which the assertion holds and the time of situation. The actual interpretation of aspectually marked sentences thus depends on the interaction between the grammatical aspectual category and properties at the level of semantic aspect. We will illustrate this frame of analysis with examples from motion events.

\section{2-state situation}

(2) The child is crossing the road. imperfective aspect not qualified source state target state not qualified

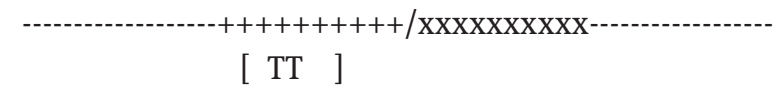

(3) The child has crossed the road.

not qualified source state target state not qualified perfect aspect

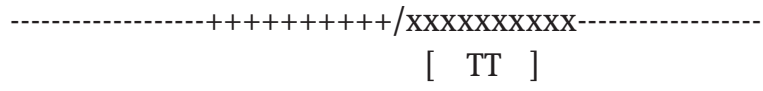

7 Most studies in this context are based on Vendler's 4-fold classification with more or less categorical refinements. As Croft (2012) notes this has resulted in an almost impenetrable terminological jungle. With our specific focus on one domain, motion events, we want to introduce a descriptive framework which allows for the description and analysis of the data in a simple and consistent way. 
(4) 'abara l-waladu ț-țāriqa

cross-PF.3SGM DEF-boy DEF-road

'the boy crossed the road'

not qualified source state target state not qualified perfective aspect

[TT]

This sketchy outline of the basic aspectual notions should suffice in describing the aspectual systems of the two Arabic varieties in the present comparison.

\subsubsection{Brief overview of the aspectual forms in MSA and TA}

MSA and TA belong to the group of aspect languages in that finite verbs are obligatorily marked for aspect, thereby leading to the selection of specific phases of a situation for assertion. MSA has a twofold aspectual opposition between a perfective (suffixed) and an imperfective form (prefixed) ${ }^{8}$ "le système verbal en Arabe classique se manifeste fondamentalement dans une opposition simple, celle de l'accompli à un inaccompli." [the verbal system in classical Arabic manifests itself fundamentally in a simple opposition between the 'accomplished' versus 'not accomplished'.] (Cohen 1989: 91). In the framework introduced above, perfective aspectual markers select a temporal relation in which the topic time includes the change of state (pre-state to post state) of a situation. The perfective selects the following phases of a situation, depending on the inherent semantics of the verb:

\section{2-state-situation}

(5) l-ummu $\quad$-näfida
open-PF.3SGF
DEF-mother DEF-window
the mother opened the window'
[TT]

8 With regard to the nature of the temporal category expressed by the verbal paradigm, some researchers argue that these forms should be classified as forms expressing tense rather than aspect (Fischer and Jastrow 1996; Eisele 1999; Brustad 2000). We adopt the position which treats these forms as aspectual markers and refer the reader to the indepth discussions in Cohen 1989; Maas et al. 2000; Singer 1984; Owens and Yavrumyan 2007; Wild 1964. 


\section{1-state- situation}

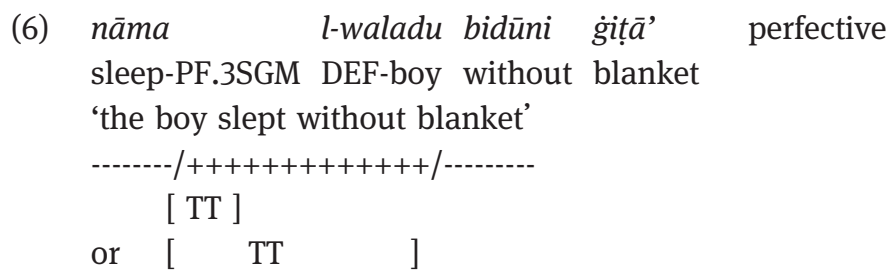

The imperfective aspectual marker selects a temporal relation between the topic time and some sub-interval of a situation:

\section{2-state-situation}

(7) taftaḥu l-ummu n-nāfida imperfective open-IPF.3SGF DEF-mother DEF-window 'the mother is opening the window' -----/+++++++++/xxxxxxxx-----------

[ TT ]

\section{1-state-situation}
(8) yasbahu l-waladu fi l-buhayra imperfective swim-IPF.3SGM DEF-boy in DEF-lake 'the boy is swimming in the lake' -------/++++++++++++/-------

[ TT ]

The imperfective is used for all situations in which the assertion does not involve a change of state, as with situations which are ongoing, habitual, or iterative.

There is a third aspectual form, the participle active (AP), which is present in MSA as well as the oral varieties, in the present case TA. This form is marked morphologically by an -ā- between the first and the second radical. It can fulfill the function of a predicate, although it is 'defective' in the sense that it is not marked for person. As Singer notes "Längst ist bekannt, dass das aktive Partizip in vielen semitischen Sprachen in der einen oder anderen Weise dem System der finiten Verbformen eingegliedert wurde." [It is a long known fact that the active participle in many Semitic languages has been categorized, in one way or another, as a member of the system of finite verbs.] (Singer 1984: 303; see also Ebert 2000: 753). While the form exists in all varieties of Arabic, its function 
differs. "The status of the active participle in Classical Arabic ${ }^{9}$ contrasts markedly with its role in spoken Arabic, where it nearly always contrasts in meaning with either an imperfect or a perfect verb." (Owens and Yavrumyan 2007: 543). He attributes "a central role to the AP in the systems of spoken Arabic" (Owens and Yavrumyan 2007: 544, see also Cohen 1986, 1989; Maas 1999; Maas et al. 2000; Brustad 2000: 170 ff.; Chaara 2003). But the question remains as to what the semantic contribution of the AP actually is in context? A look at the literature presents a confusing picture: (see Wild 1964: 240), "the use of the AP is difficult to describe" (Owens and Yavrumyan 2007: 544), "das aktive Partizip kann zum Ausdruck von 'présent actuel', 'prospectif' oder 'parfait' dienen" [the active participle can serve to express 'present actual', 'prospective', or 'perfect'] (Jemni 2011: 84). The reason for this rather puzzling picture lies in the nature of grammatical aspect as a twofold relational category: a) depending on the verbal basis, an aspectual marker selects a specific subinterval of a situation (topic time in relation to time of situation) and b) the topic time, $i$. e., the temporal viewpoint has to be anchored either in relation to speech time (topic time includes time of utterance) or in relation to some other event time. The latter provides the basis for implications with respect to time of reference. There seems to be a consensus, however, that the AP has a resultative reading (Wild 1964) in that it selects the post state of a 2-state situation (Example (9)) and the intermediate state of a 1-state situation (Example (10)).

(9) rāğel hāall l-karhba

man open-AP.3SGM DEF-car

'a man has opened the car'

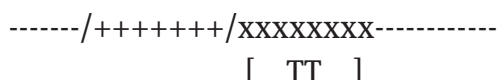

(10) rāğel rāged 'a l-ḥ̌ššs

man sleep-AP.SGM on DEF-straw

'a man has (fallen) asleep, and is therefore sleeping on the straw'

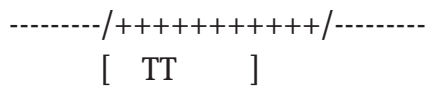

As Jemni notes in his comprehensive description of Tunisian, "Durch das aktive Partizip wird das Resultat einer Handlung stärker betont als durch die Suffixkonjugation." [Through the active participle the result of an action is

9 Owens and Yavrumyan use the term Classical interchangeably with Standard Arabic in this chapter on the AP (cf. 2007: 543). 
emphasized to a greater degree compared to the suffixconjugation] (Jemni 2011: 85). He agrees with Ebert (2000) in saying that "das arabische aktive Partizip, im Grunde genommen ein Resultativ ist, das bei transitiven Verben eine 'perfect'Lesart einnehmen kann und bei den inchoativen und Bewegungsverben eine 'perfect or actual present meaning' [the active participle in Arabic, is in effect a resultative, which functions as a 'perfect' with transitive verbs and with inchoatives and motion verbs has a 'perfect or actual present' meaning]. (Jemni 2011: 88) ${ }^{10}$

As an adequate overview of the current debate among Semitists on the AP at a systematic level is beyond the scope of this study, the discussion will be restricted to the domain of motion verbs. Our contribution in this field proceeds from the bottom up, given its empirical basis. The documentation of actual patterns of use will add a further facet on the use of the AP. The field of motion verbs is mentioned specifically in descriptions of the AP (c. f. Chaara 2003; Caubet 1993) as Brustad (2000) notes: "The biggest problem presented by the participle as a grammatical form is that a small category dominated by participles of motion seem to behave in an altogether different manner than the participles cited above. Rather than indicating the resultant state of a prior act, these particular motion participles often indicate progressive aspect." (Brustad 2000: 185). In conclusion Brustad (2000: 175) notes that the way in which the participle functions in the aspectual systems of the spoken varieties of Arabic is still not fully understood.

\subsubsection{Motion events as a specific case}

Use of the perfective, given the case of path verbs, requires a temporal point of reference which may be located at the beginning of a motion event, signaling entry into a situation (d dahaba MSA: 'go (away or to)' PF.3SGM; mša TA: 'move' ('go away or to') PF.3SGM, or at the end of an event, signaling a point of completion (wașala MSA: 'arrive' PF.3SGM; dxal TA: 'enter' PF.3SGM). ${ }^{11}$ The

10 Eisele takes a different position in saying that the resultative reading of the AP is not the characteristic reading (cf. 1999: 133 on Cairene Arabic). He follows a different line of argumentation in interpreting the aspectual markers in their time referential, i. e., tense-equivalent potential. The AP of motion verbs "indicates a future state or event" (p. 142). Since this is clearly not the case in the present data, and it is also not the position advocated in the present paper, we will not pursue this discussion further.

11 Brustad notes that the participles are widely used in spoken varieties (2000: 182), expressing either a progressive or the resultant state of a change-of-state predicate. She also addresses the problem of verbs of translocation (p. 185, fn. 10), where she points out that there is no systematic research on this topic so far. 
two varieties do not show differences in form-function relations with respect to the perfective. Path verbs (Examples (12), (14)), as well as manner verbs (Examples (11), (13)) in the perfective, describe a situation as completed.

(11) MSA: rakaḍa l-kalbu fi s-sāha

run-PF.3SGM DEF-dog in DEF-court

'the dog ran in the court'

(12) MSA: daxalat as-sayyāra ilā mabnā

enter-PF.3SGF DEF-car to building

'the car is entered a building'

(13) TA: țol ğra fi l-ğnīna

boy run-PF.3SGM in DEF-garden

'a boy ran in the garden'

(14) TA: qațtos dxal li l-bìt

cat enter-PF.3SGM to DEF-room

'a cat entered the room'

With regard to the question of the imperfective, it is necessary to consider the two systems separately. In MSA there are no constraints on the use of the imperfective at the level of viewpoint and the inherent semantics of the verb: the imperfective can be used for directed as well as undirected motion and singular as well as habitual situation types. There is no difference between path (Example (16)) and manner verbs (Example (15)) as regards constraints on the use of the imperfective.

(15) MSA: imra'a tatajawwalu fì l-madīna woman go-out-IPF.3SGF in DEF-town 'a woman is going for a walk in the town'

(16) MSA: al-bintu tadxulu ilā l-kanīsa

DEF-girl enter-IPF.3SGF to DEF-church 'the girl is entering the church'

In TA the opposition between the imperfective and the AP can be described as follows. Path verbs in AP-form are to be interpreted as progressives which mark a path as leading incrementally up to a goal point or leading away from a source 
point. Note that with the AP the state of reaching the endpoint or a goal region is not asserted (Jemni 2011: 88; Owens and Yavrumyan 2007: 545).

TA: rāğel dāxel li s-supermarché
man enter-AP.3SGM to DEF-supermarket
'a man is entering the supermarket'

By contrast, the imperfective cannot be used in the context of goal-oriented motion.

In motion events, the perspective taken, given use of the imperfective, is that of a situation without an envisaged goal.
TA: rāğel yhạwwes
fi $\check{s}$-šāri
man go-out-IPF.3SGM in DEF-street
'a man is going out for a walk in the street'

This means that most manner verbs in TA do not show use of the AP form since these verbs do not allow for a 2-state reading. If a manner verb is used it has to be in the imperfective. "Reine activity-verbs (wie laufen, rennen - added by the authors) sind mit der partizipialen Form nicht kompatibel.”[Pure activity verbs (such as walk, run, - added by the authors) are not compatible with the participle form.] (Jemni 2011: 88)

In addition to morphological aspectual markers, Arabic has aspectual verbs to express selected phases of an event. These periphrastic constructions are used to different degrees, however, in MSA compared to the spoken varieties. The form frequently used in TA is the co-verb qã 'id ('sit'-AP.3SGM) combined with a full verb in the imperfective (cf. Saddour 2010). Saddour describes the meaning of this construction as follows: “ $q a$ :'id plays a purely aspectual role in progressive contexts. It is a preverbal PRG marker that is still in a process of grammaticalization [...]" Furthermore, it is not used systematically when a situation is described as on-going at a certain time, like the case of V-ing in English". (Saddour 2010: 132, Saddour 2009). However, the status of this periphrastic form as a progressive is not undisputed in the literature (Jemni 2011: 144). Use of this form will be investigated in the present study with respect to its semantics and level of grammaticalization, as observed in the context of motion events.

In summarizing this brief survey of the aspectual systems in their relevance for the comparison between TA and MSA in the context of motion events, we find substantial differences between MSA and TA. MSA has a two-fold aspectual opposition between the perfective and imperfective. TA, by contrast, features a three-fold system consisting of the imperfective, perfective, and the AP with 
progressive/perfect meaning. This indicates that the perfective-imperfective opposition does not have the same 'value' in the two varieties.

\subsection{Typological classification of MSA and TA: domain of space}

MSA has a rich lexicon of path verbs. In typological surveys it is classified as a verb-framed language (Talmy 2000). Studies on the use of the deictic motion verbs (e. g., dahaba 'go away' and ðâ'a/atâ 'come'; cf. Blohm and Jumeili 1983) have drawn comparisons between the Arabic system and English (see also Bernini 2010: 12; Abdulrahim 2013). The majority are typically corpus studies, however, in which parameters concerning the actual context of use cannot be readily reconstructed and are thus of limited relevance in the present context. The study by Alshehri (2014), on the expression of self-motion in English and Arabic covers five manner verbs of motion and their integration into a semantic frame at the sentence level. The description is based on literary texts (MSA) as well as colloquial Egyptian, which is problematic for comparisons of use. ${ }^{12}$ Furthermore, the author does not take typological differences into account with their implications for the use of manner verbs. The conclusion whereby verbs in Arabic tend to profile manner of motion more than English verbs, while verbs in English profile path of motion more frequently than in Arabic (2014: 21) is counterintuitive. The reported findings are misleading due to an analysis on the basis of similar forms (manner verbs) without taking into consideration the status of these forms within the respective system.

In checking the features of verb-framed languages as outlined above, TA offers a mixed picture. Compared to MSA, there are even less studies on motion verbs in TA or other spoken varieties of Arabic. Saidi (2006) focuses on reference to space while Al Murshidi's analysis (2013) of the use of motion verbs in the spoken varieties of the Gulf region ${ }^{13}$ shows that speakers use more path verbs than manner verbs in narrative contexts (cf. 2013: 73).

With regard to motion events, the number of path verbs in TA is limited, compared to MSA, as there are no verbs that explicitly express direction with a goal orientation (e. g., to advance toward $x$, to head for $x$ ). This means that a

12 Problems associated with type of data base can also be observed in Bernini (2010: 12-14), in which a typological analysis on spatial relations in motion events is based on an Arabic corpus which is a translation of an English novel. According to the judgements by native speakers, the translation shows non-native like examples in the data presented in the article.

13 In Al Murshidi (2013) speakers come from the United Arab Emirates, Saudi-Arabia, Oman, and Qatar. 
principal feature of verb-framed languages is not found in TA. In other respects, however, TA conforms to a verb-framed pattern. Information on the path of motion encoded in prepositions does not include contours of the ground (of the type 'along', 'over', 'around'). A note is in order with respect to the verb mša, which is used frequently in the present study and generally translated as 'to walk'. In TA the meaning has bleached in the sense that it is no longer restricted to a particular manner of motion (cf. data in Alshehri 2014). It can be viewed rather as a neutral verb, expressing what Talmy has called motion without the notion of manner or path. This classification is not indisputable, and we will come back to this point in the discussion of the empirical data. In conclusion, we can say that both languages share features which hold as verb-framed, but differ in the lexical repertoire relating to the path of motion.

\subsection{Comparison and open questions}

As outlined above, MSA and TA display substantial differences in the means of expression in the domains of space and time, although closely related. They are both aspect languages but do not share the same system of aspectual oppositions. As will be shown below, the means in TA provide more fine-grained distinctions with respect to temporal perspective-taking and phasal decomposition. With regard to the question 'verb-framed' TA does not have path verbs that explicitly encode the concept of direction.

We assume therefore that speakers of both languages will differ in the conceptualization and expression of motion events. Given the absence of specific distinctions in TA at the level of the lexicon, grammaticalized aspectual categories may play a role in structuring the motion event. The general idea has been formulated in Beavers et al. (2010) as follows: "the wide variation in motion event encoding falls out from general constraints on how manner and path may be encoded in language, together with independent properties of the morpholexical inventories and morphosyntactic resources of particular languages.” (Beavers et al. 2010: 40, emphasis added by the authors). The potential interaction with aspectual categories, however, is not considered in what is called a 'revisited typology of motion expressions'.

\section{The empirical study: design and methodology}

Visual stimuli were developed which vary with respect to (a) the temporal phases of the motion event depicted and (b) the spatial properties direction (goal 
oriented), the ground, and manner of motion. These parameters allow the investigation and comparison of how speakers construe motion events under a specific temporal perspective.

\subsection{Stimuli}

The stimuli consisted of a set of 70 dynamic real-world video clips showing different event types. Each video clip lasted six seconds and was preceded by a blank screen with a focus point. The blank screen varied in length with 8 seconds in the "standard" condition and 4 seconds in a "time pressure" condition. The role of time pressure was to test stability in the use of specific linguistic forms. This has been carried out for markers of progressive aspect in evolving systems (e. g., Dutch) and established as a paradigm in Carroll and Flecken (2012). In the given context the time pressure condition serves to indicate the stage of grammaticalization of periphrastic aspectual forms, along with overall consistency in the use of specific aspectual markers.

The event types consisted of a set of 30 motion events and a set of 40 filler items. All motion event scenes involved self-propelled locomotion of the following types: type A showed a figure in motion (a vehicle, person, animal etc.), moving along a short trajectory (on a road, side walk, stretch of grass, etc.) towards a highly evident goal point marked by an object (a house, a gate, petrol station, playground, etc.). Type B showed a figure moving along an extended trajectory with a potential, but not an evident goal point (a village or a house in the distance). Type C comprised motion events in which a goal was reached, thus showing a boundary crossing (examples from screenshots of the stimuli) (Figure 1).

The filler items consisted of different events involving causative actions (e. g., a person knitting a scarf, building a model airplane) activities (e. g., a person jogging, playing the flute) and 'low level' changes of state (e. g., a candle burning, ice cream melting on a plate). Each recording was preceded by a training session with 6 items from all categories.

The session started with the following instruction, which participants were asked to read: You will see a set of video clips showing everyday events which are not in any way connected to each other. Before each clip starts, a blank screen with a white focus point will appear. Please focus on this point, since this allows us to proceed to the next video clip. Your task is to tell "what is happening", and you may begin as soon as you recognize what is happening in the clip. It is not necessary to describe the video clips in detail (e. g., "the sky is blue"). Please focus on the event only. Instructions were given in Tunisian Arabic and Modern 

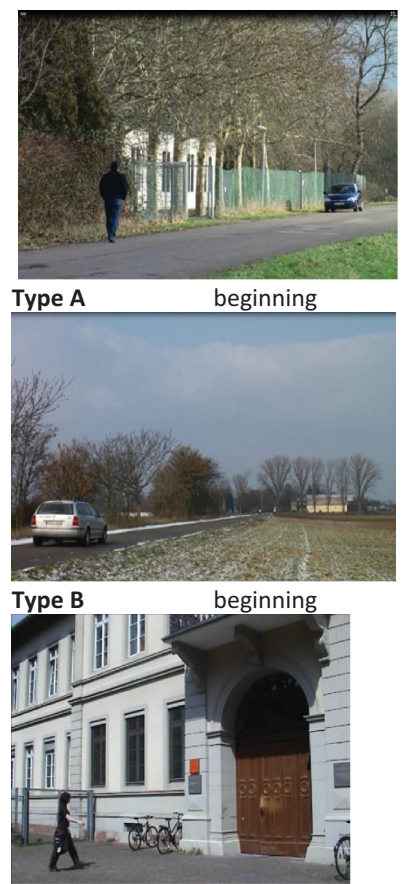

Type C

beginning

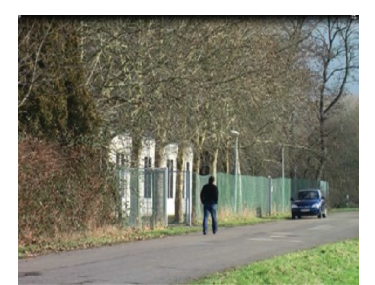

intermediate

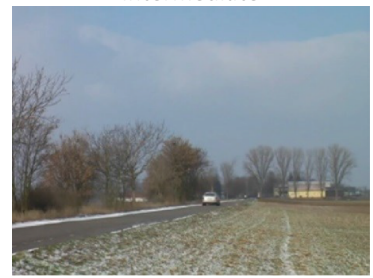

intermediate

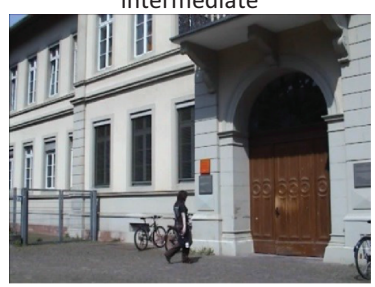

intermediate

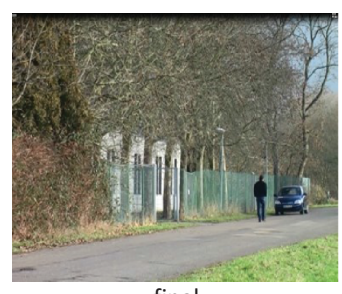

final

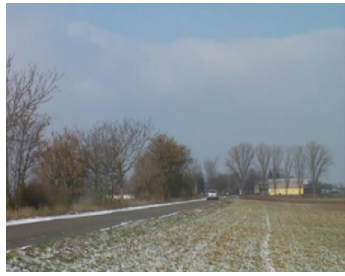

final

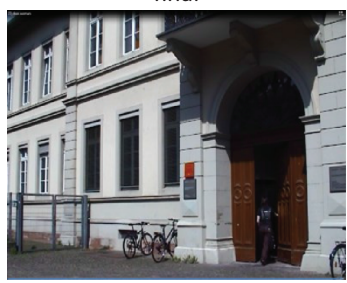

final

Figure 1: Motion events.

Standard Arabic with the following final request for language production:

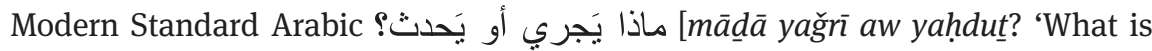

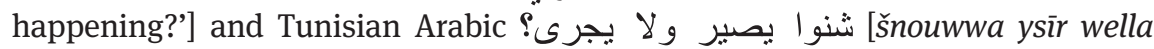
yeğrā?'What is happening?']. The research assistant spoke either TA or MSA with the participants in the experiment. The participants' descriptions and eye movements were recorded during the task. ${ }^{14}$ They were also asked to fill out a questionnaire on their educational and linguistic background at the end of the recording.

\subsection{Participants, recordings and coding procedure}

Speakers of Arabic were recruited at the Institutes for Semitic languages at the universities of Göttingen and Heidelberg. All participants had a comparable

14 The eye tracking data will not be analyzed in the present study. 
social background (third level education). Tunisian speakers (7 female, 12 male) were from the Northern part of Tunisia and aged between 18 and 26. The group speaking Modern Standard Arabic (3 female 16 male), were aged between 19 and 38. They were from the following Arabic speaking countries: Morocco (1), Tunisia (11), Egypt (1), Saudi Arabia (2), Palestine (1) and Syria (3). The MSA speakers from Tunisia did not participate in the study on Tunisian. ${ }^{15}$ All speakers were paid $10 €$ for their participation. The recorded data were transcribed and coded with respect to aspectual and spatial categories covering both verb types (path, manner) for both language groups. All transcripts and codings were checked by a second researcher.

\section{Results}

\subsection{Decomposition of events into two sub-events}

As pointed out in Talmy (2000), speakers of verb-framed languages show a tendency to subdivide an event into two subevents when an entity is on its way to a goal which is finally reached: the first subevent ${ }^{16}$ encoded in a separate clause relates to manner of motion with a locative preposition (or no locative) such as a car is driving (on a road), while the second relates to the path of motion, e. g., a path verb and mention of the place at goal as in it is entering a yard (see also Carroll et al. 2012). This two-clausepattern was also observed in the Arabic data - in TA more frequently than in MSA - and corresponds to findings for verb-framed languages in earlier studies.

Example from Tunisian Arabic

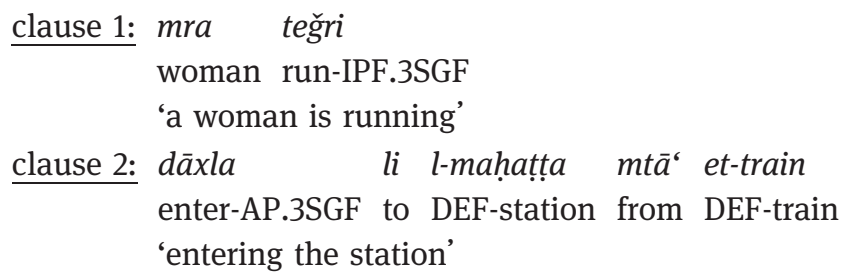

15 With regard to knowledge of other languages, speakers from North African countries also had knowledge of French.

16 This part is termed co-event in Talmy's terminology (2000). 
This typically occurs in the present data base with Type C, (goal reached) or where a potential goal is evident (Type A):

The difference between the two languages is not significant: for type $\mathrm{A}: \chi^{2}(1$, $\mathrm{N}=423)=3.146, p=0.076$; for type $\mathrm{B}: \chi^{2}(2, \mathrm{~N}=396)=4.551, p=0.103$; for type $\mathrm{C}$ : $\chi^{2}(2, \mathrm{~N}=382)=2.032, p=0.362$. Descriptions with two utterances will therefore not be included in the following quantitative analyses as a variable in the language comparison (Figure 2). The numbers of utterances on which all figures are based is presented in Table 1:

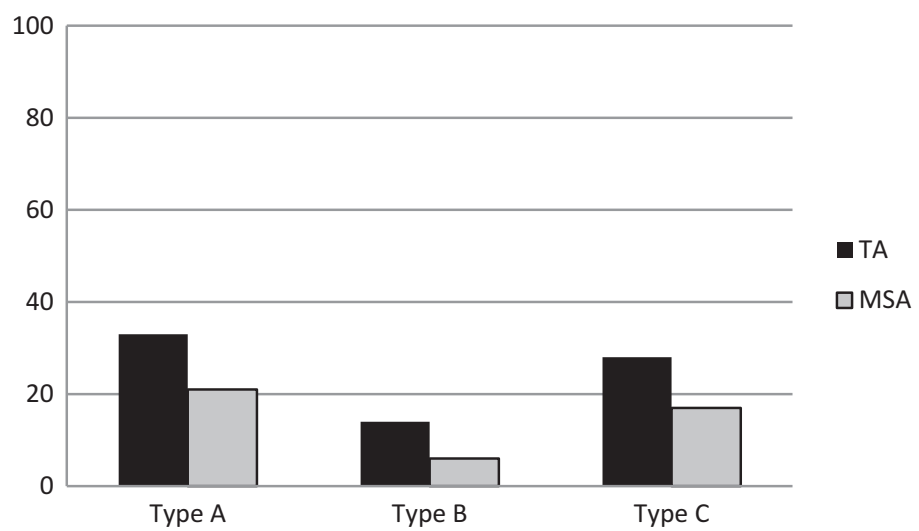

Figure 2: Number of event descriptions with two utterances per motion event type in Tunisian Arabic and Modern Standard Arabic.

Table 1: Database.

\begin{tabular}{lrrr}
\hline & Type A & Type B & Type C \\
\hline MSA minus time pressure & 210 & 194 & 184 \\
MSA plus time pressure & 200 & 193 & 174 \\
TA minus time pressure & 222 & 200 & 201 \\
TA plus time pressure & 213 & 192 & 179 \\
\hline
\end{tabular}

\subsection{Aspectual marking}

The following section starts with the data for Tunisian Arabic and concerns the use of aspectual markers and their level of grammaticalization (+/- time pressure condition). Figure 3 presents the findings for the three different types of motion events. 


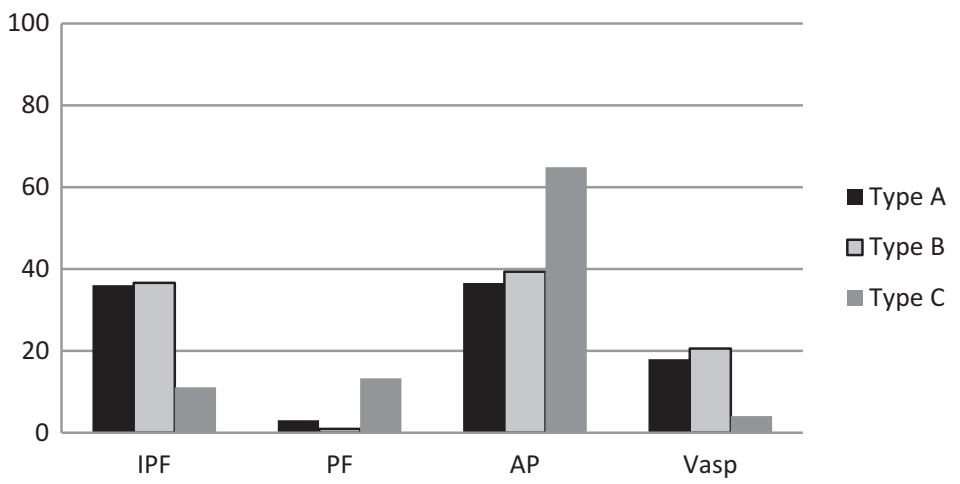

Figure 3: Aspectual markings in TA without time pressure (percentages).

The results indicate how aspect is related to the variable event type. ${ }^{17}$ Events in Type $C$ (end point reached) were more likely to be expressed by the participle and show a low occurrence of the imperfective. ${ }^{18}$ Type A (short trajectory with evident endpoint) and B (long trajectory, endpoint not clear) evidenced a more or less equal distribution of the imperfective and participle. The distribution indicates the presence of clear attractors and constraints for the different event types: The frequent occurrence of the participle when the event involves a boundary crossing, as in Type $\mathrm{C}$, points to the semantic link between the participle and a two-state situation (cf. Section 2.3.3 above): use is observed with references to the beginning of a motion event (move away from $\mathrm{x}$ ), the intermediate section (pass by $\mathrm{x}$ ) or the end point (move to $\mathrm{x}$ ). The form exhibits features of a progressive in the sense of progression from one state to the next, $\mathrm{i}$. e., directed motion. This perspective can be selected if a measure for segmentation can be applied, which in motion events is not given by the event itself but by the presence of a reference point on the way. This can be a boundary which has been crossed (the states preceding and following a boundary crossing (enter $\mathrm{x}$ ), or the viewing point of a deictic observer is passed by (pass by $\mathrm{x}$ ).

Based on the data, we will show that in the context of motion events the participle has developed into a full progressive which has to be used in predicates with change-of-state verbs, as with enter, pass by (Example (20)).

17 A more detailed analysis of the semantic components of the utterances will provide evidence for the constraints on the different aspectual forms (cf. Figure 12 below).

18 The few instances of the imperfective form occur in the context of causative motion verbs such as ydaxxel 'make enter' in rāğel ydaxxel fi karhebtu l-el-garage 'a man is taking his car into the garage'. 
$\begin{array}{rll}\text { (20) TA } m r a \quad d \bar{x} x l a & \text { li l-magazin } \\ \text { woman enter-AP.3SGF to DEF-shop }\end{array}$

Use of the imperfective is not an option in these contexts. The version in MSA where speakers have to use the imperfective (Example (21a)) is ungrammatical in TA (Example (21b)):

$\begin{array}{lllll}\text { a: MSA } & \text { mar’atun } & \text { tadxulu } & \text { ilâ } & \text { d-dukkân } \\ & \text { woman } & \text { enter-IPF.3SGF } & \text { to } & \text { DEF-shop } \\ \text { b: TA } & { }^{*} \text { mra } & \text { tedxul } & \text { li } & \text { l-magazin } \\ & \text { woman } & \text { enter-IPF.SGF } & \text { to } & \text { DEF-shop }\end{array}$

In contrast to the participle, the periphrastic verb construction $q \bar{a}^{\prime} i d+$ lexical verb was not used in conjunction with mention of a goal. The few occurrences in type $\mathrm{C}$ were limited to verbs that express undirected motion such as somebody going for a walk (one-state verbs such as yetmešš 'to walk slowly' or yhawwes 'to go for a walk') in combination with a locative preposition or zero. In contrast to Saddour's claim, we did not find evidence in our data of a progressive meaning for the periphrastic aspectual form. Since the speakers described the events shown in the clips while unfolding in front of their eyes, the periphrastic form expresses a perspective that relates to "what is happening now"?

With regard to the different aspectual distinctions, use of the imperfective was restricted to a static temporal perspective, combined with prepositions that mark a location. The perfective was used in a few cases only, mainly in relation to type C. It expresses a temporal perspective that focuses the post state of the boundary crossing event: they (have) entered (perfective) the house. The fact that the participle has gained the status of a grammaticalized progressive means that the contexts to which this form now applies are no longer covered by the imperfective ${ }^{19}$ (cf. Brustad 2000; Chaara 2003).

As mentioned above, a time pressure experiment was used to test the level of grammaticalization of these forms (Figure 4). The period of time between the clips - the period showing a blank screen - was reduced from 8 to 4 seconds. Under this condition, use of the periphrastic form $q \bar{a}$ ' $i d$ 'sit'- AP.3SGM combined with a full verb in the imperfective almost disappeared, while use of the imperfective clearly increased. Use of the participle, by contrast, was not affected. It remained constant, thus indicating differences in status in the

19 This level of grammaticalization for the participle is also documented for Moroccan Arabic in Chaara (2003: 90). 


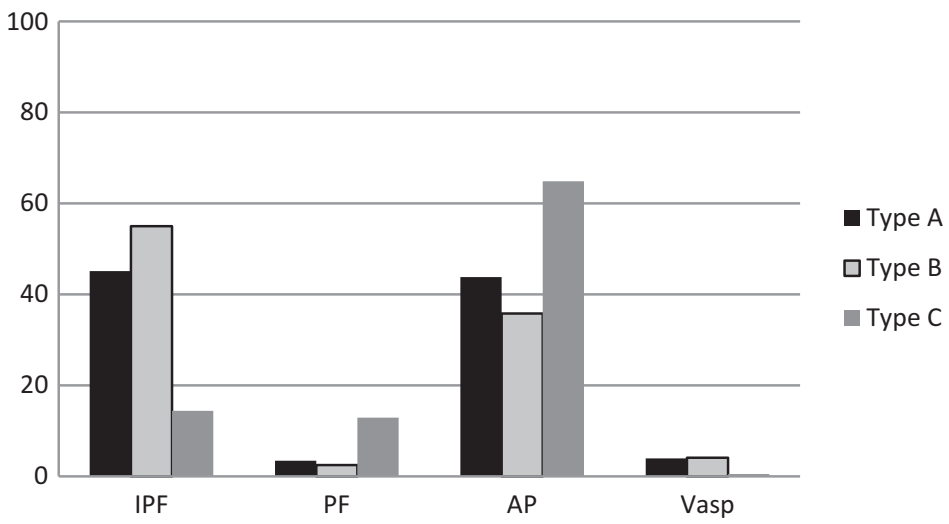

Figure 4: Aspectual markings time pressure condition in Tunisian Arabic (percentages).

system. A qualitative analysis of the distribution across conditions shows that the periphrastic form was replaced by the imperfective, while the participle remained unaffected in its distribution.

Figure 5 presents an overview over the three types of events with the variable +/- time pressure.

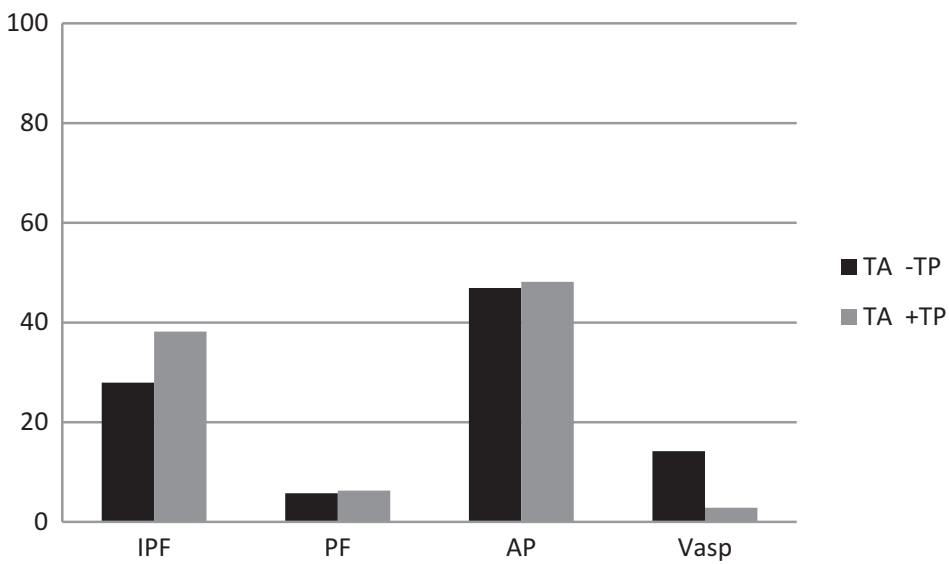

Figure 5: Comparison of aspectual markers across conditions +/- time pressure (percentages).

The increase in the use of the imperfective from the 'no time pressure' to the 'time pressure' condition was significant $\chi^{2}(1, \mathrm{~N}=1208)=13.112, p=0.000$, as was the decrease of the $\operatorname{Vasp} \chi^{2}(1, \mathrm{~N}=1208)=50.268, p=0.000$. The difference 
observed for the use of the particle was not significant, $\chi^{2}(1, \mathrm{~N}=1208)=0.766$, $p=0.382$. The same applies to the perfective forms - also not significant $\chi^{2}(1$, $\mathrm{N}=1208)=0.24, p=0.624$.

We conclude from these findings that the periphrastic form is optional and does not constitute a systematic aspectual opposition. In other words, there is no evidence in the context of this study that it would occupy a unique semantic space within the aspectual system of TA. Use of the participle, by contrast, was not affected by the time pressure condition. Its status is further underlined in that certain types of situations can only be expressed by a participle, as will be shown below (Figure 12). All observations point to its status as a third aspectual form that constrains the domain of the imperfective, in accordance with descriptions of TA in the literature (Saddour 2010).

The findings for the distribution of aspectual markers take on a different picture for Modern Standard Arabic. As shown in Figure 6, the imperfective was used across all types of motion events. Although the other forms exist, occurrences were very low.

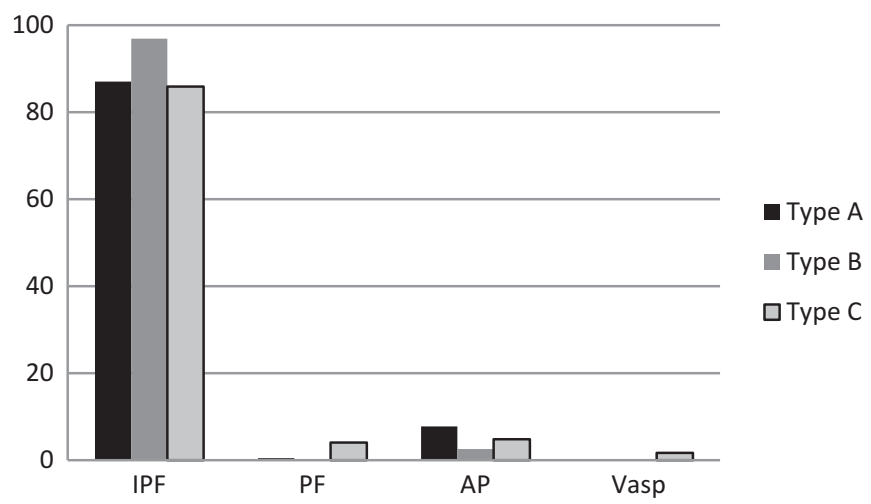

Figure 6: Aspectual markers in MSA (percentages).

The stability of the basic two-fold aspectual system - imperfective/ perfective is further confirmed by the time pressure data which showed no effect with regard to the aspectual markers in MSA. Use of the perfective was very low. This can be attributed to the fact that the $C$ type situation does not show the final phase of completion where the figure in motion has actually reached the region within the place at goal beyond the boundary crossing

Comparing the results for the two varieties of Arabic, we can conclude that the classification of the two languages, as found in the literature, is confirmed in the present study. There are two aspectual systems whereby MSA shows a 
twofold opposition between the imperfective and the perfective. TA evidences a threefold system with the participle as an aspectual form which is not interchangeable with other forms without a change in event type (use of the imperfective given undirected and/or habitual motion versus use of the AP with directed motion). This is not the case with the periphrastic form in TA. It is optional, highlighting a specific temporal feature which is similar, for example, to the periphrastic aspect markers in German (am Arbeiten sein 'at the work be'). Figure 7 provides an overview of the aspectual markers used in the two languages, merging the three event types.

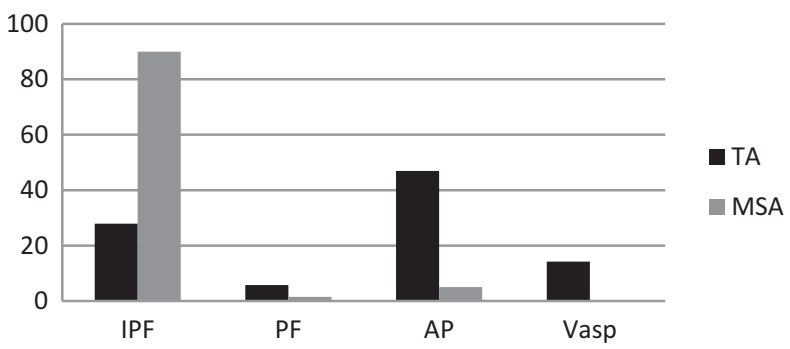

Figure 7: Aspectual markers in MSA and TA for all event types (percentages).

The first step in the analysis has yielded evidence of clear differences between the two varieties in the domain of grammatical aspect. The differences reach significance for all four forms: imperfective $\chi^{2}(1, \mathrm{~N}=1201)=494.251, p=0.000$, perfective $\chi^{2}(1, \mathrm{~N}=1201)=15.809, p=0.000$, participle $\chi^{2}(1, \mathrm{~N}=1201)=261.554$, $p=0.000$, Vasp $\chi^{2}(1, \mathrm{~N}=1201)=79.203, p=0.000$.

The following section focuses on the spatial concepts selected for the three types of motion events, as packaged in verbs and prepositional phrases, with special emphasis on the interrelation between spatial and aspectual properties of the event descriptions. Spatial information is categorized as expressed in forms which correspond to the type "prepositional phrase".

\subsection{Spatial concepts and expressive devices}

\subsubsection{Verb types}

The forms cover manner, path as well as neutral verbs, whereby the latter forms are neutral with respect to manner and path in that they simply encode motion. As argued above, the Tunisian verb $m$ ša (frequently translated as 'to walk') is 
neutral with respect to manner and path in the sense that it applies both to vehicles as well as persons, (covering drive and walk in English, for example). Figures 8 and 9 present the results ${ }^{20}$ for the distribution of the different verb types across event types per language.

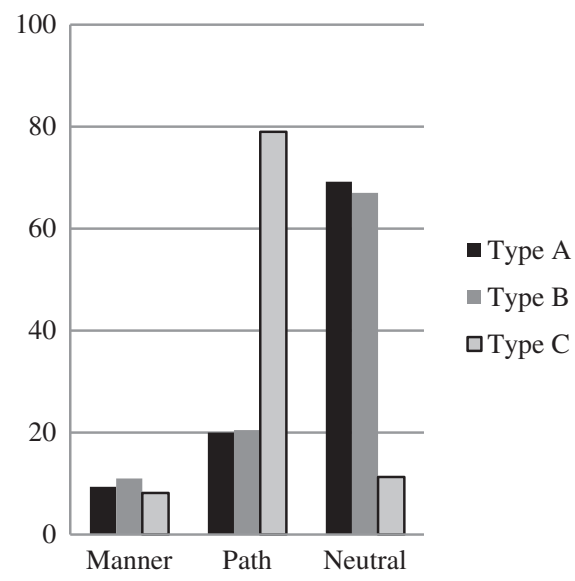

Figure 8: Tunisian Arabic, types of verbs (percentages).

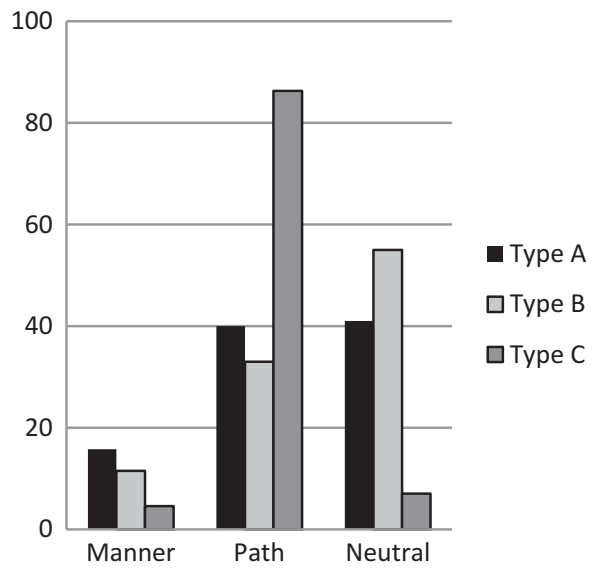

Figure 9: Modern Standard Arabic, types of verbs (percentages).

The points the languages have in common as well as their differences are as follows: In accordance with the observations for verb-framed languages,

20 There are a few instances of zero copula constructions such as a man in a car park or a car on the road which are included in the sample, adding up to $100 \%$, but not shown in the graph. 
speakers of both varieties expressed boundary crossing events by means of path verbs (Type C). Use of path verbs by MSA speakers was significantly higher, however, compared to the TA speakers (typically the verb daxala (MSA) and dxel (TA) 'to enter'), which occurred at a rate of $87 \%$ in MSA and $77 \%$ in TA, respectively $\left(\chi^{2}(1, \mathrm{~N}=382)=5.811, p=0.016\right)$. The few manner verbs used in the Type $\mathrm{C}$ events (goal reached) are predicates in the first utterances of two unit descriptions. In contrast to the second unit, the first utterance does not relate to the path of motion, as mentioned above.

There is also a significant difference between the two varieties with respect to the use of path verbs in the situation types $A$ and $B$ (for type $A \chi^{2}(1, N=423)=$ $17.040, p=0.000$; for type $\left.\mathrm{B} \chi^{2}(1, \mathrm{~N}=386)=6.219, p=0.013\right)$. TA evidenced fewer occurrences ( $20 \%$ versus $38 \%$ in MSA) but also fewer types. While the speakers of MSA showed a range of path verbs, e. g., dahaba 'to go', ittağaha 'to direct oneself', ibta'ada 'to depart', 'abara 'to cross', ințalaqa 'to leave', iqtaraba 'to approach', this is not the case in TA. Path verbs were not used in TA, bar one exception: the verb t'adda 'to pass', which does not encode direction. In other words, the concept of directionality is represented in the verb and related to the figure in motion in MSA, just as, for example, in French (cf. Carroll et al. 2012), but this is not the case in TA. ${ }^{21}$

\subsubsection{Spatial forms}

Speakers of both languages referred to components of the different paths traversed in the events shown in the clips by means of prepositional phrases. However, as in the case of the verbs, there is an important difference between the MSA and TA lexicon regarding the expression of directed motion. MSA has a preposition that encodes direction to a goal, the preposition nahwa 'toward' (71 occurrences).This form was used by speakers in addition to the preposition ila 'to'. In contrast to MSA, TA speakers used the preposition li 'to' in similar contexts. Prepositions marking "location” (forms of the type $f i / f i$ 'in' or 'alā/'la 'on') were used by both groups. The forms used are categorized as follows, illustrated by examples from MSA:

Location sayyāratun tasīru 'alā š-šāri' 'a car is driving on the road'

Trajectory sayyāratun tattağihu naḥwa 'a car is directing itself towards the l-madinati town'

goal rağulun yadxulu l-kanisata 'a man is entering the church'

21 A comprehensive list of motion verbs used by both group of speakers is in the appendix. 
The category "zero" relates to predicates such as in a woman is walking (Figure 10).

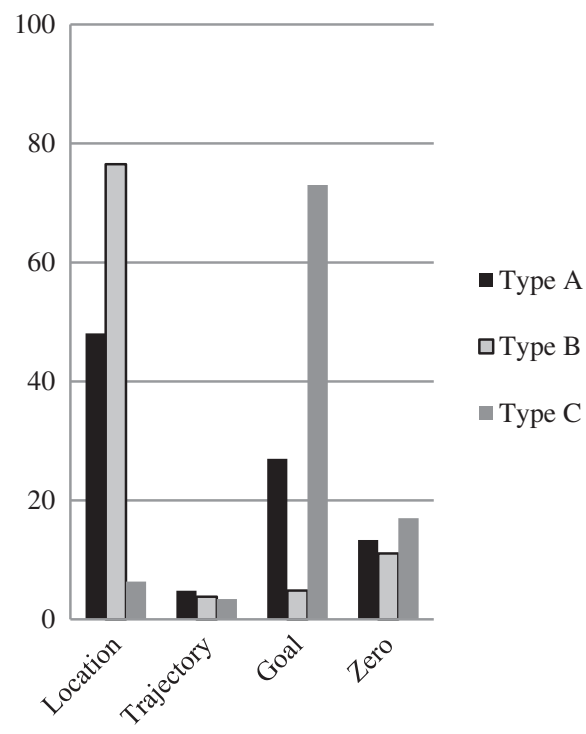

Figure 10: TA, prepositions (percentages). Note: There are a few instances in which speakers do not express directed motion but rather expressions such as to stroll. They do not refer to a place and were thus coded as "minus preposition". This group is not represented in the graph but adds up to the $100 \%$.

Again we find similar preferences as well as significant differences (Figure 11). With the situation type $\mathrm{C}$ (endpoint reached) the picture for the two languages is similar with respect to the relevant types marking "goal", "location" and "trajectory" (goal: $\chi^{2}(1, \mathrm{~N}=382)=0.045, p=0.833$; location: $\chi^{2}(1, \mathrm{~N}=382)=$ $0.91, p=0.763$, trajectory: $\left.\chi^{2}(1, \mathrm{~N}=396)=0.434, p=0.510\right)$. The two groups differed, however, with the event types A (short trajectory) and B (long trajectory). For type A the difference is significant for "trajectory" $\chi^{2}(1, \mathrm{~N}=423)=$ $27.078, p=0.000)$ and "goal" $\left.\chi^{2}(1, \mathrm{~N}=423)=9.088, p=0.003\right)$, while for type B the difference reaches significance for "location" $\chi^{2}(1, N=396)=13.662$, $p=0.000$ and "trajectory" $\left.\chi^{2}(1, \mathrm{~N}=396)=24.100, p=0.000\right)$. While MSA speakers provided information on "trajectory" ( $30 \%)$, such as in the example mar'atun tattağihu naḥwa l-mabnā ('woman directs herself-IPF towards DEFbuilding'), information on this component was very low in TA. The difference between TA and MSA for "trajectory" for both types A and B is highly significant $\chi^{2}(1, \mathrm{~N}=819)=149.239, p=0.000$. This finding will be taken up again below as it is relevant for the way forms of this kind interact with the aspectual distinctions. 


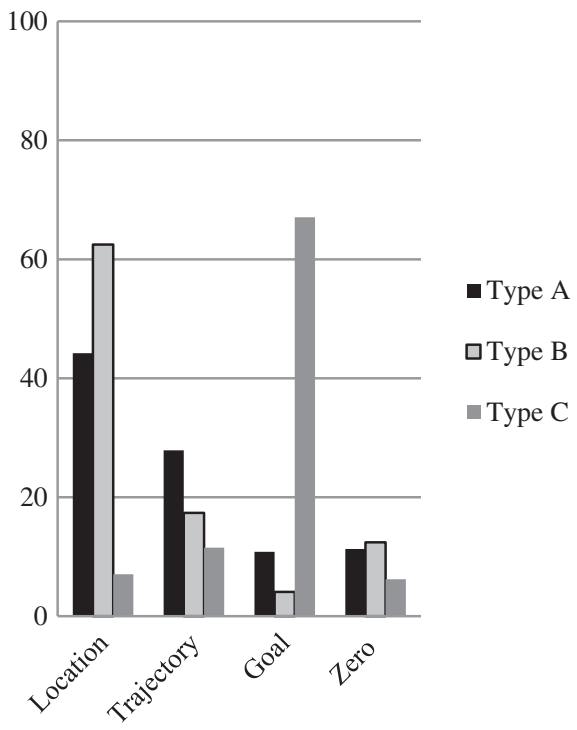

Figure 11: MSA, prepositions (percentages).

\subsection{Aspect and type of preposition}

With regard to the interrelation between aspectual form and the use of concepts encoded in prepositions, in overall terms, the collocation between aspectual form and the different prepositions once again provides evidence of the contrasts between the two systems with respect to information distribution. ${ }^{22}$ In TA, information marking transitions at the boundary of a place at goal was restricted to predicates marked for aspect via the participle. Specification of "trajectory" was very low and the state-like aspectual forms (imperfective and periphrastic verb) co-occurred with "location" or "zero" only. In TA, we can thus observe a dependency between the temporal category of aspect and the type of motion event encoded by the sentence. This is not the case in MSA, where, by contrast, imperfective aspect combines with any of the categories listed (Figure 12).

22 Since there are only a few occurrences of the perfective and the future, they were not included in the statistics. However, the interrelation between aspect and the use of prepositional forms is also clearly constrained. The perfective $(n=38)$ occurred with "goal" $(73 \%)$ or "trajectory "(18\%) or zero (9\%), but never with "location" (in/on); for the future $(n=22)$ "goal” at (70\%), "trajectory" (4\%) and "zero" (23\%). 


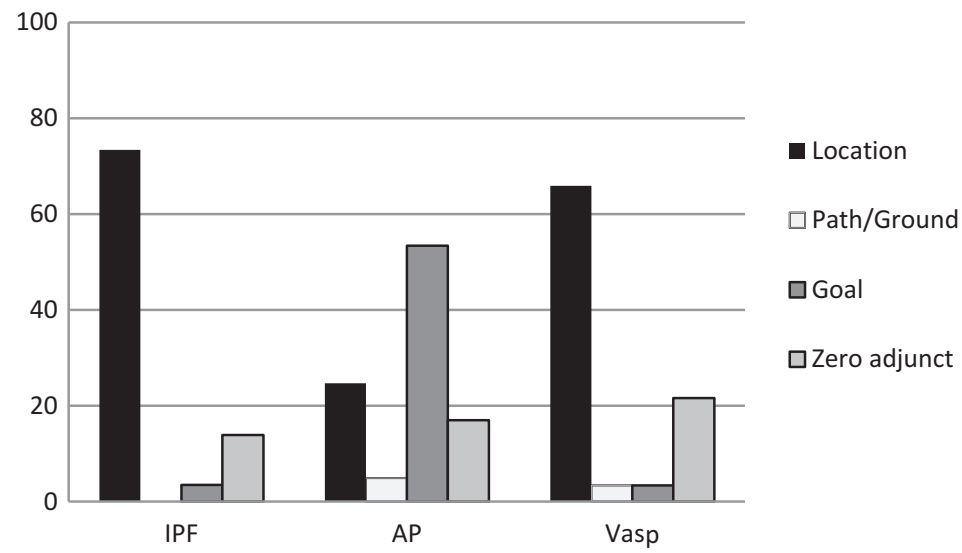

Figure 12: TA, aspect + preposition.

Use of the participle was observed in events showing a transition away from source (karhba māšya 'a car move away', karhba māšya f-el-kayes 'a car move away on the road') or to a goal with proximity to the boundary (rāğel māši 1karhebtu 'a man move to his car'). In aspectual terms the moving entity is encoded via a verb in the form of a participle, as having made the transition from the state of being on one side of a boundary, to the state of being on the other side. The role of aspect is again highlighted with events in which the verb pass was used, as with Type B (long trajectory with a possible goal). The entity "being passed" in this case, the reference point for the transition involved, is a point in the field of vision of the observer viewing the clips. Typical examples in TA are given under (25):
a. karhba met'addya fi ț-trīq car pass-AP.3SGF in DEF-road 'a car (is) passing on the road'
b. karhba met'addya
car pass-AP.3SGF
'a car (is) passing'

As indicated above, there is no feature on the ground in the clips shown which could function as an entity "being passed by". The point of reference in question is the viewing point of the observer.

The findings for both verbs and prepositions show that the speakers of MSA provided more information on directionality, trajectory with information 
packaged in verbs as well as prepositions. The range of categories, as expressed in TA, were more or less confined to static components (either "location" as on the road or "goal"). The case of what could be called missing dynamics in the expression of motion events in TA, in terms of concepts encoded in prepositional forms, falls into place, however, when the following features are taken into account: the temporal domain, as profiled by a specific aspectual distinction, constitutes a core component in the conceptualization of motion events.

\section{Discussion of the results}

This study on the conceptualization of motion events by speakers of Modern Standard Arabic and Tunisian Arabic was based on three situation types, shown in the form of video clips, which profile the following set of event components: Type A situations showing motion on a short path leading directly to a place at goal which is visible but not reached by the figure in motion; Type B with motion on an extended path without a visible goal point, but with pronounced contours (e. g., around, up, along); type C) a short path leading to a goal with a boundary crossing. The most important difference between TA and MSA concerns the inventories for the expression motion events. MA has a wide range of path verbs and all options are in evidence in this study. Apart from the repertoire for boundary-crossing events, (two state verbs such as enter), TA lacks specific verbs of directed motion. Verbs in MSA (ittağaha 'to direct oneself', iqtaraba 'to approach' and dahaba 'to go away') have no equivalents in TA. Instead, TA speakers use the neutral verb mša 'to move' with a high frequency.

While TA, compared to MSA, has fewer verbs that express directed motion at a lexical level, its aspectual system is richer. MSA has a grammaticalized opposition between the imperfective and perfective, allowing the selection of two phases of a motion event for assertion: the state preceding and following an explicit boundary crossing, marked explicitly by the perfective as completed. The imperfective, however, does not provide any information on the dynamics of a situation. The dynamics of the situation can be inferred on the basis of world knowledge. A figure in an event involving a change in place, expressed by a path verb, has to be in the process of moving. TA, by contrast, has a grammaticalized progressive via the participle which implies a succession of states (e. g., a figure moving away from a place at source followed by the state of having moved away). Use of the participle with motion verbs implies this form of temporal succession. Translational motion can be expressed by the meaning of the verbs involved (e. g., pass) and this component is supported in aspectual terms by the participle. 
With regard to the way the path of motion is structured via prepositional forms, the preposition expressing direction in MSA is (nahwa 'toward'), while TA has the preposition $l i$ 'to' which relates in directional terms to the goal at a place. Apart from the range of path verbs, the principal difference between the two varieties concerns the role of aspectual means in encoding directed motion in TA.

\subsection{Descriptions of type A}

In this event type, where a potential goal can be extracted from the video scene, references in both TA and MSA are carried out by means of directional terms. In TA, references with (li 'to') amount to (25\%). In MSA, nahwa, 'toward' (29\%) occurs with path verbs to mark the trajectory, while mention of a goal with other forms amounts to $9 \%$, giving a total of $38 \%$. Path verbs in MSA (40\%) show a range of different types, in contrast with TA, where the neutral verb mša, which expresses motion, dominates at (65\%). Path verbs in TA $(20 \%)$ consist of two types 'pass', and 'enter'. While occurrences of the latter form reflect the tendency to construe motion events as goal oriented, driven by the semantic requirements of the participle (a boundary or other point of reference), pass provides the semantic basis for use of the participle given the presence of a deictic viewing point (pass by) and thus does not require an external object at ground. These constructions yield the following patterns of event construal for the two languages:

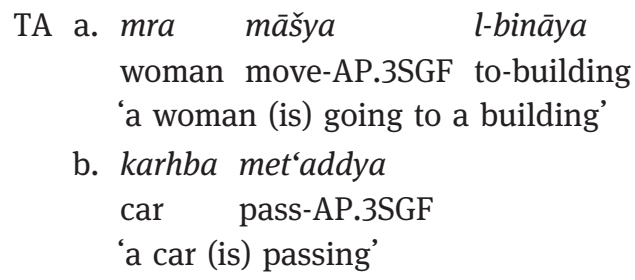

b. karhba met'addya car pass-AP.3SGF

'a car (is) passing'

(24) MSA a.
a. aț-țiflatu tattağihu
nahwa l-bāb
DEF-girl direct-oneself-IPF.3SGF towards DEF-door the girl heads towards the door'
b. sayyâra tasīr
car move-IPF.3SGF
'a car drives'

Taking a closer look at the motion events in which a figure is encoded as on its way, the two varieties of Arabic differ as follows: TA does not have a form of the 
type 'toward' ("trajectory"). As described above, the means used in TA entail spatial points of reference which segment the path into sections In addition to the verb pass, which encodes translational motion, this component is also implied by the aspectual form of the progressive, as encoded by the participle. In MSA temporal information does not function in profiling changes in place. This is encoded by the verb with spatial concepts encoded in prepositions to provide information on the orientation and the direction of the moving entity.

With regard to features of the path traversed, however, references are confined to the location of the figure and expressed by prepositions in both varieties. In TA, a form expressing "location" can combine with a participle, a construction not found in MSA.

\section{(25) karhba mâðya fi l-kayâs \\ car move-AP.3SGF in DEF-road \\ 'a car (is) going on the road'}

The one-state motion verb $m s ̌ a$ in participle form translates as 'move away' given the fact that the participle implies transitions in terms of a point of reference, thereby involving a succession of states. This example again indicates how the temporal category of aspect interacts with spatial concepts expressed in verbs in the construal of motion events (see Type B below).

The situation differs when the imperfective and the periphrastic form are used in TA, as the imperfective in TA cannot be used in the context of directed motion. The same holds for the aspectual verb. With regard to the selection of spatial forms, a clear semantic constraint can be observed given exclusive use of "location" or a "zero":
a. tofla $q \bar{a}$ 'da temši
girl sit-AP.3SGF move-IPF.3SGF
'a girl (is) walking' (Vasp + IPF)
zero
b. rāğel qāa'ed yemši fi l-kayās
man sit-AP.3SGM move-IPF.3SGM in DEF-road
'a man (is) walking on the road' (Vasp + IPF) location

The prepositions used in locating the figure in motion are either $f i$ 'in', or ' $l a$ 'on', or nominal expressions such as 'at the edge', 'in the middle'. The place referred to is conceptualized as a property of the entity, explicitly expressed by the "sit and move' construction. The aspectual category is "ongoingness" and the motion event is profiled as frozen in time, so to speak. This interpretation is supported by the following observations: a) in a large number of cases the 
lexical verb is a manner verb, which relates to constant properties of the figure in focusing the manner in which it moves; b) the high occurrence of the category "zero", with no information on the route. The moving entity is assigned the property of 'moving' for some specific temporal interval without further information.

MSA, by contrast, does not present different perspectives on the motion events via aspectual distinctions as the imperfective is the only option. If a situation is described with a specification of "location", e. g., fi ('in the road') and 'alā ('on the road'), this occurs mainly in conjunction with manner verbs or the neutral verbs mašā and sāra. "Location" does not combine with path verbs that are figure-based and mark orientation/trajectory toward a goal, but with pass, a verb which includes features of the ground. Here we also see similarities with the TA system in that information is not provided on the dynamics of the situation, apart the lexical meaning provided with the verb. So we have at the spatial level the location of a figure at a place (in the middle of a road, on the road) and can infer from the verb meaning that there will be a change of place in line with the temporal implications of a motion event as involving changes of state.

\subsection{Descriptions of type B}

Type B scenes are characterized by a long trajectory and a remote potential goal about which no information is provided. The routes shown were varied with respect to contours (e. g., 'along', 'over', 'around') which speakers of satellite framed languages (English, German) focus when describing the path of motion. Their overall absence in TA as well as MSA serves in indicating their status as languages in which information on the path traversed is verb framed.

In this event type, the two groups of speakers again present different solutions. In TA, descriptions are frequently based on the neutral verb mša, this time with mention of "location" (78\%) and an increase in the number of participle forms compared to type A results. Again, core information on the dynamics of the situation is conveyed in aspectual form, while spatial information has to be inferred, as transitions both between and across states are encoded at the level of aspect. Again, continuation of the figure in motion on the path is marked by specifying its overall location. In MSA, by contrast, the selection of the different categories as well as the distribution of relevant information across conceptual domains is similar across the event types A and B (short and long trajectory). 


\subsection{Descriptions of type C}

In this event type (boundary crossing at goal) speakers of both languages use two-state path verbs in combination with the category goal ('toward' and 'to'). In TA use of the participle is required in this context, while in MSA the aspectual form used is the imperfective. This means that while the spatial information encoded in the verb and other forms is comparable for the two groups, the temporal perspective on the event differs. In TA, speakers relate to a process in explicit terms, and translational motion is part of the meaning encoded in the verb. With respect to a boundary crossing at goal, the number of speakers that mark the post state of the boundary crossing event by means of the perfective aspect is low (this phase was not explicitly shown in the clips). Speakers of both groups do not differ in the selection nor distribution of information across the different linguistic means in spatial terms. They differ, however, in the temporal profile of the forms used in focusing different aspects of the motion event.

In summary, the analysis presents a consistent picture. With regard to situations with a short trajectory and an evident goal, the two languages show significant differences. MSA has path verbs that are figure-based and encode its orientation, direction toward a goal, while TA does not have path verbs of this kind. The verbs in TA include features of the ground ("pass", "enter") and are thus ground-based. In addition to these features, fundamental differences have been identified for the temporal domain and its role in TA. In TA, the participle is the only aspectual option that can combine with mention of a goal, while in MSA, the form used in this context is the imperfective. In reference to situations where a figure is on its way without an evident goal, the systems diverge, given the differences between the verbal and prepositional inventories. In overall terms, speakers of both varieties show different options with respect to the perspectives they select. We identified two patterns: one in which the event is under focus with a dynamic description and one in which the figure is under focus, with no information on the path of motion. In this latter case locomotion is presented as a property of the figure (e. g., a woman walking). With regard to the spatial information encoded, this is similar for the two groups of speakers: the forms are manner verbs or neutral verbs which combine with a locative prepositional phrase or zero.

The imperfective, which is used with manner verbs, does not contribute information on the event type and is unmarked in this respect in MSA. In TA, by contrast, the imperfective is more restricted in its semantics given its opposition to the AP. It occurs in references to habitual situations and properties. Its use in 
the context of a specific situation indicates that the event is profiled as a property of the entity. Specific spatial components of the event are not focused.

Speakers also use a verb which has bleached to the general meaning of motion only. Significantly, this is where the role of aspectual forms comes to the fore. The participle, which is the adequate form in referring to motion events that are viewed as directed, requires a point of reference which can be implemented given places at source or goal. The progressive expresses a process involving a series of states that are incremental, which in the case of motion events implies translational motion. Note, however, that under this division of labor in TA, explicit information on the trajectory drawn through space is not provided. In this context, the solution adopted in MSA presents a different set of options. The means used provide information on direction to a goal, thereby encoding the orientation of the figure in space by means of both verbs and prepositions. Aspectual distinctions do not play a role in profiling spatial components of the event.

\section{Interaction between aspect and spatial concepts in a typological framework}

In these concluding remarks we argue for a richer typology of motion events based on the role and interaction of a wider range of language resources. The analysis and comparison of the two Arabic varieties, MSA and TA, provided evidence not only of common features but also marked differences which confirm the presence of a variety of motion event framing patterns within one type. The data show, furthermore, that there are also options within one language in the selection of a particular conceptual frame, options which may diverge from the core features of the basic type the language is assigned to. The challenging question which now arises concerns the possible overall logic and relevant parameters underlying the complex ramifications of motion event descriptions.

Let us start with the common features. Arabic is classified as a verb-framed language in the literature (cf. Talmy 1985, 2000; Slobin 2006: 62). In accordance with some of the critical criteria in Talmy's framework (cf. Flecken et al. 2015 as well as the discussion in Croft et al. 2010: 13), the Arabic varieties investigated show the following features: (a) path verbs or neutral verbs show precedence over manner verbs, (b) a motion event can be described by means of a bare predicate without spatial anchorings, (c) absence of prepositions or other forms to express boundary crossings,(d) related to this fact, manner verbs do not 
combine with forms expressing a boundary crossing, (e) locative forms are used to anchor the figure on the path (ground as location).

The differences we observe in the descriptions of events of directed motion are rooted on the one hand in the lexical inventories. Verbs and their morphological properties determine the selection of other elements. The fact that TA lacks explicit path verbs to express directed motion implies constraints in the encoding of motion events which differ from MSA given its rich repertoire in this domain. A fundamental feature of verb framed languages is absent in TA, however. The main verb is neutral with respect to path and manner. How can a neutral motion verb, combined with information focusing location, be sufficient in describing motion events involving changes in place? So far, explanations for the different patterns were rooted in the conceptual domain of space. The comparison between MSA and TA indicates that the absence of path verbs in the expression of directed motion "is compensated for" by temporal aspect in the form of progression. Progression, in a strict sense, implies directed motion in the present context. The present empirical findings show how the typology of motion event studies can be extended to include aspectual categories .of this kind. Variation is not confined to the conceptual categories under focus so far such as figure, path, ground, manner (and causative actions). Grammaticalized categories on verbs - in this case aspectual markers - have fundamental implications in profiling event types. Aspect in this form also presents an interesting phenomenon of de-metaphorization. Progression is a spatial concept (from Latin progressus, stem progred- 'move forward') which has been metaphorically extended to the abstract conceptual domain of time: moving ahead on the one-dimensional time line. In this sense it can be viewed as directed, given no other option for moving in time, in contrast to space. The integration of this temporal concept in descriptions of motion events furnishes the concepts typically expressed with verbs or spatial means: it profiles a motion event as specific and directed towards some point of change on the way. The comparison of two varieties, which are usually treated as belonging to one type, has shown that it necessary to focus other areas of analysis in addition to space in order to gain further insight into the systematicity in the diversity of encoding options. Time is an important domain in the typology of motion events.

Acknowledgements: We would like to thank the DFG (German Research Foundation) for financial support. For valuable comments and help with the data we wish to thank Wolfgang Klein, Monique Lambert, Pascale Leclerc, Agnieszka Tytus and Brigitte Greiling. We are also grateful to two anonymous reviewers for their detailed and valuable input. 


\section{References}

Abdulrahim, Dana. 2013. A corpus study of basic motion verbs in Modern Standard Arabic. Edmonton, Alberta: University of Alberta dissertation. https://docs.google.com/file/d/ 0B6bAv9MbSv29QmdKOHVPdkdLQXc/edit?pli=1 (accessed 22 June 2014).

Al Murshidi, Ghadah. 2013. The expression and conceptualization of motion through space and manner of motion in Arabic and English: A comparative analysis. In Serafín M. Coronel-Moli (ed.), Working papers in literacy, culture, and language education, vol. 2, 57-76. School of Education, Indian University Bloomington. http://education.indiana.edu/ graduate/programs/literacy-culture-language/specialty/wplcle/WPLCLE\%20Volume\%202 \%20-\%20May\%202013.pdf (accessed 22 July 2014).

Alshehri, Ali Mohammad. 2014. The frame semantics of 'selfmotion' frame in Arabic and English. San Francisco: San Francisco State University MA thesis. http://www.askalin guist.org/uploads/2/3/8/5/23859882/ali_the_frame_semantics_of_self-motion_frame_ in_arabic_and_english.pdf (accessed 30 June 2014).

Aske, Jon. 1989. Path predicates in English and Spanish: A closer look. Proceedings of the Fifth Annual Meeting of the Berkeley Linguistics Society 1-14.

Beavers, John, Beth Levin \& Shiao Wei Tham. 2010. The typology of motion expressions revisited. Journal of linguistics 46. 331-377.

Bernini, Giuliano. 2010. Word classes and the coding of spatial relations in motion events: A contrastive typological approach. In Giovanna Marotta, Alessandro Lenci, Linda Meini \& Francesco Rovai (eds.), Space in language: Proceedings of the Pisa International Conference, 29-52. Pisa: ETS.

Blohm, Dieter \& Monem Jumeili. 1983. Zur Semantik der arabischen Verben dahaba '(weg) gehen ' und ğā'a/atā 'kommen'. Zeitschrift für Phonetik, Sprachwissenschaft und Kommunikationsforschung 36(1). 128-134.

Bloom, Paul, Mary A. Peterson, Lynn Nadel \& Merrill F. Garrett (eds.). 1996. Language and space, Cambridge, MA: Massachusetts Institute of Technology Press.

Bohnemeyer, Jürgen, Nicholas J. Enfield, James Essegbey, Iraide Ibarretxe-Antuñano, Sotaro Kita, Friederike Lüpke \& Felix K. Ameka. 2007. Principles of event representation in language: The case of motion events. Language 83(3). 495-532.

Bohnemeyer, Jürgen \& Mary Swift. 2004. Event realization and default aspect. Linguistics and Philosophy 27(3). 263-296

Brustad, Kristen. 2000. The syntax of spoken Arabic. A comparative study of Moroccan, Egyptian, Syrian, and Kuwaiti dialects. Washington, DC: Georgetown University Press.

Carroll, Mary \& Monique Flecken. 2012. Language production under time pressure: Insights into grammaticalisation of aspect (Dutch, Italian) and language processing in bilinguals (Dutch, German). In Bernt Ahrenholz (ed.), Einblicke in die Zweitspracherwerbsforschung und Ihre methodischen Verfahren, 49-76. Berlin \& Boston: De Gruyter.

Carroll, Mary, Katja Weimar, Monique Flecken, Monique Lambert \& Christiane von Stutterheim. 2012. Tracing trajectories: Motion event construal by advanced L2 French-English and L2 French-German speakers. Language, interaction and acquisition (LIA) 3(2). 202-230.

Caubet, Dominique. 1993. L'Arabe marocain: Syntaxe et catégories grammaticales, Tome 2. Paris: Peeters. 
Chaara, Fadoua. 2003. Die Interaktion der Aspektsemantik mit dem Lexikon im MarokkanischArabischen. Munich: Lincom

Cohen, David. 1986. La phrase nominale et l'évolution du système verbal en semitique : Études de syntaxe historique. Paris: Peeters.

Cohen, David. 1989. L'aspect verbal. Paris: Presses Universitaires de France.

Comrie, Bernhard. 1976. An introduction to the study of verbal aspect and related problems. Cambridge: Cambridge University Press.

Croft, William. 2012. Verbs: Aspect and clausal structure. Oxford: Oxford University Press.

Croft, William, Jóhanna Barðdal, Willem B. Hollmann, Violeta Sotirova \& Chiaki Taoka. 2010. Revising Talmy's typological classification of complex event constructions. In Hans Boas (ed.), Contrastive studies in construction grammar, 201-235. Amsterdam \& Philadelphia: John Benjamins.

Dahl, Östen. 1985. Tense and aspect systems. Oxford: Blackwell.

Ebert, Karen H. 2000. Aspect in Maltese. In Östen Dahl (ed.), Tense and aspect in the languages of Europe, 753-785. Berlin \& New York: Mouton de Gruyter.

Eisele, John C. 1999. Arabic verbs in time: Tense and aspect in Cairene Arabic. Wiesbaden: Harrassowitz.

Fischer, Wolfdietrich \& Otto Jastrow. 1996. Lehrgang für die arabische Schriftsprache der Gegenwart, Band 1. Wiesbaden: Reichert Verlag.

Flecken, Monique, Mary Carroll, Katja Weimar \& Christiane von Stutterheim. 2015. Driving along the road or heading for the village? Conceptual differences underlying motion event perception and description in French, German and French-German L2 Users. Modern Language Journal 99(S1). 100-122.

Herskovits, Annette. 1986. Language and spatial cognition. An interdisciplinary study of the prepositions in English. Cambridge: Cambridge University Press.

Jemni, Karim. 2011. Tempus, Aspekt und Modalität im Tunesischen Arabisch und die Entwicklung der Kategorie Auxiliare. Munich: LINCOM.

Klein, Wolfgang. 1991. Raumausdrücke. Linguistische Berichte 132. 77-114.

Klein, Wolfgang. 1994. Time in language. London: Routledge.

Klein, Wolfgang. 2010. On times and arguments. Linguistics 48(6). 1221-1253.

Maas, Utz. 1999. Die Entwicklung des neuarabischen Verbalsystems am Beispiel des Marokkanischen. In Edzard Lutz \& Mohammed Nekroumi (eds.), Tradition and innovation. Norm and deviation in Arabic and Semitic linguistics, 124-167. Wiesbaden: Harrassowitz.

Maas, Utz, Selmy EL-Sayed \& Ahmed Mostapha. 2000. Perspektiven eines typologisch orientierten Sprachvergleichs Deutsch-Arabisch, Arabisch-Deutsch. Kairo: Echnaton

Matsumoto, Yo \& Dan I. Slobin. 2005. A bibliography of linguistic expressions for motion events, part 1. http://www.lit.kobe-u.ac.jp/ yomatsum/resources/motionbiblio1.pdf (accessed 5 December 2014)

Miller, George A. \& Philip N. Johnson-Laird. 1976. Language and perception. Cambridge, MA: Harvard University Press.

Monteil, Vincent. 1960. L'Arabe moderne. Paris: Klincksieck.

Owens, Jonathan \& Marat Yavrumyan. 2007. The Participle. In Kees Versteegh, Mushira Eid, Alaa Elgibali, Manfred Woidich \& Andrzej Zaborski (eds.), Encyclopedia of Arabic language and linguistics, 541-546. Leiden: Brill.

Rouchdy, Aleya. 2002. Language contact and language conflict in Arabic. London: Routledge Curzon. 
Ryding, Karin C. 2005. Reference grammar of Modern Standard Arabic. Cambridge: Cambridge University Press.

Ryding, Karin C. 2011. Modern Standard Arabic. In Stefan Weninger (ed.), The Semitic languages. An international handbook. (Handbücher zur Sprach- und Kommunikationswissenschaft 36), 844-850. Berlin: Mouton de Gruyter.

Saddour, Inès. 2009. The expression of progressivity in Tunisian Arabic: A study of progressive markers in oral retellings of simultaneous situations. Revue de Sémantique et Pragmatique 25-26. 265-280.

Saddour, Inès. 2010. Relating two simultaneous events in discourse: The role of ongoingness devices in L1 Tunisian Arabic, L1 French and L2 French by Tunisian learners. Birmingham: Aston University dissertation.

Saidi, Darine. 2006. Étude typologique de l'expression de déplacement en arabe tunesien. Paper presented at the Colloque International d'Étudiants Chercheurs en Didactique des Langues et Linguistique, University Stendhal-Grenoble 3, 4-7 July.

Salameh, Franck. 2010. Language, memory, and identity in the Middle East: The case for Lebanon. Lanham: Lexington Books.

Sasse, Hans-Jürgen. 2002. Recent activity in the theory of aspect: Accomplishments, achievements, or just non-progressive state? Linguistic Typology 6(2). 199-271.

Singer, Hans-Rudolf. 1984. Grammatik der arabischen Mundart der Medina von Tunis. Berlin \& New York: Walter de Gruyter.

Slobin, Dan I. 2006. What makes manner of motion salient? Explorations of linguistic typology, discourse, and cognition. In Maya Hickmann \& Stéphane Robert (eds.), Space in languages: Linguistic systems and cognitive categories, 59-81. Amsterdam \& Philadelphia: Benjamins.

von Stutterheim, Christiane \& Ralf Nüse. 2003. Processes of conceptualization in language production. Linguistics 41(5). 851-881.

von Stutterheim, Christiane, Martin Andermann, Mary Carroll, Monique Flecken \& Barbara Schmiedtová. 2012. How grammaticized concepts shape event conceptualization in language production: Insights from linguistic analysis, eye tracking data and memory performance. Linguistics 50(4). 833-867.

Talmy, Leonard. 1975. Semantics and syntax of motion. In John P. Kimball (ed.), Syntax and semantics, vol. 4, 181-238. New York: Academic Press.

Talmy, Leonard. 1983. How language structures space. In Herbert Pick \& Linda Acredolo (eds.), Spatial orientation: Theory, research, and application, 225-282. New York: Plenum.

Talmy, Leonard. 1985. Lexicalization patterns: Semantic structure in lexical forms. In Timothy Shopen (ed.), Language typology and syntactic description: Grammatical categories and the lexicon, vol. 3, 57-149. Cambridge: Cambridge University Press.

Talmy, Leonard. 2000. Toward a cognitive semantics. Cambridge: MIT Press.

Wild, Stefan. 1964. Die resultative Funktion des aktiven Partizips in den syrischpalästinensischen Dialekten des Arabischen. Zeitschrift der Deutschen Morgenländischen Gesellschaft 14(2). 239-254.

Wunderlich, Dieter \& Michael Herweg. 1991. Lokale und Direktionale Verben. In Arnim von Stechow \& Dieter Wunderlich (eds.), Semantik: Ein internationales Handbuch zeitgenössischer Forschung, 758-785. Berlin \& New York: Mouton de Gruyter. 


\section{Appendix. Types and frequency of verbs used}

\begin{tabular}{|c|c|c|}
\hline Path-verbs & $\begin{array}{l}\text { Verbs in MSA } \\
\text { daxala (127) } \\
\text { 'to enter' } \\
\text { ittağaha (73) } \\
\text { 'to direct oneself' } \\
\text { dahaba (32) } \\
\text { 'to go' } \\
\text { marra (19) } \\
\text { 'to pass' } \\
\text { șa'ada (10) } \\
\text { 'to climb, to go up' } \\
\text { 'abara (8) } \\
\text { 'to cross' } \\
\text { iqtaraba (6) } \\
\text { 'to approach' } \\
\text { tawaqqafa (5) } \\
\text { 'to stop' } \\
\text { xarağa (5) } \\
\text { 'to exit, to go out' } \\
\text { qașada (4) } \\
\text { 'to direct oneself' } \\
\text { ibta'ada (4) } \\
\text { 'to depart, to get away' } \\
\text { wașala (4) } \\
\text { to arrive' } \\
\text { ințalaqa (3) } \\
\text { in'ațafa (2) } \\
\text { to turn' }\end{array}$ & $\begin{array}{l}\text { Verbs in TA } \\
\text { dxal (155) } \\
\text { 'to enter' } \\
\text { t3adda (46) } \\
\text { 'to pass' } \\
\text { dār (11) } \\
\text { 'to turn' } \\
\text { țla' (8) } \\
\text { 'to climb, to go up' } \\
\text { wqef (7) } \\
\text { 'to stop' } \\
\text { rāh (3) } \\
\text { 'to go' } \\
\text { ğa (3) } \\
\text { 'to come' } \\
x r e g ̌ ~(3) \\
\text { 'to exit, to go out' }\end{array}$ \\
\hline Path verbs & total $(302)$ & total (236) \\
\hline Manner verbs & total (58) & total (64) \\
\hline Neutral verbs & total (220) & total (285) \\
\hline
\end{tabular}

